УДК 664.858.8

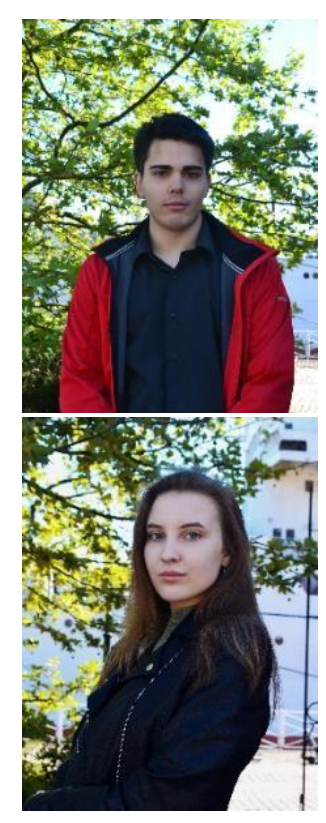

\section{ТЕХНОЛОГИЯ ПАСТИЛЫ И МАРМЕЛАДА ПОВЫШЕННОЙ БИОЛОГИЧЕСКОЙ ЦЕННОСТИ}

Д. А. Петрухин, студент 3-го курса, e-mail: denisrussia2000@gmail.com ФГБОУ ВО «Калининградский государственный технический университет»

Е. Д. Ковалева, студент 3-го курса, e-mail: kovaleva_k_30@mail.ru

ФГБОУ ВО «Калининградский государственный технический университет»

Н. Ю. Ключко, канд. техн. наук, доц., e-mail: natalya.kluchko@klgtu.ru,

ФГБОУ ВО «Калининградский государственный технический университет»

Во всём мире широко распространены кондитерские изделия, особое место среди которых занимают так называемые мармеладно-пастильные изделия (МПИ). В нашей стране эта группа представлена довольно широким ассортиментом и пользуется большим спросом среди населения, особенно среди молодёжи. Эти факты дают основания для разработки или совершенствования методов, позволяющих снизить калорийность данной продукции, а также повысить их энергетическую и пищевую ценность. В статье рассмотрены запатентованные методы обогащения пастилы полезными для человеческого организма компонентами и перспективы внедрения в рецептуры указанного кондитерского изделия биологически ценных веществ. Предложен ряд рецептур мармелада и пастилы, который может быть задействован в качестве технологической основы с учётом современных тенденций, существующих при производстве МПИ.

Ключевые слова: мармелад, пастила, обогащенный продукт, мармеладнопастильные изделия, технологии приготовления, маркетинговые исследования, анализ рынка

\title{
ВВЕДЕНИЕ
}

Пастила - пастильное изделие, изготовленное из фруктово-ягодного пюре, которое содержит большое количество пектиновых веществ, микроэлементов и других биологически активных веществ и позволяет улучшить функцию желудочно-кишечного тракта. В зависимости от студнеобразующей основы, формирующей пастильные изделия, они подразделяются на следующие виды: клеевая, где пюре из фруктов взбивается, для закрепления пенообразной и мелкопористой консистенции в него добавляют специальный «клей» в виде агаро-сахаро-паточного сиропа; заварная - приготавливается с использованием мармеладной массы; бесклеевая - делается из фруктового пюре и взбитых белков.

Актуальность исследований по совершенствованию технологий приготовления МПИ определяется прежде всего тем, что исследуемая пищевая продукция пользуется большим спросом у населения нашей страны. Кроме того, в настоящее время актуальным 
вопросом является укрепление защитных сил организма к вирусным и инфекционным заболеваниям. Известно, что нормальная микрофлора кишечника принимает участие в созревании клеток иммунной системы, таким образом обеспечивая усиление защитных свойств организма. Для её нормального функционирования необходимо постоянное поступление в организм балластных веществ, источником которых могут выступать МПИ. Помимо всего прочего, в отличие от других сахаристых кондитерских изделий, МПИ могут оказывать профилактический эффект на организм человека за счёт содержания в их составе студнеобразователей.

\section{ОБЬЕКТЫ И МЕТОДЫ ИССЛЕДОВАНИЯ}

В качестве исследуемых объектов выступили МПИ, а именно пастила и мармелад. Был рассмотрен ассортимент продаваемых в Калининграде данных кондитерских изделий в магазинах торговых сетей «Spar», «Светофор», «Виктория», «Брусничка» и др. Потребителями МПИ было пройдено интернет-тестирование в виде анкетирования для выявления спроса на мармелад и пастилу.

\section{ЦЕЛЬ И ЗАДАЧИ ИССЛЕДОВАНИЯ}

Целью настоящей работы является анализ научно-технической и патентной литературы в части совершенствования технологии производства мармеладных изделий и пастилы, в том числе повышения их биологической ценности. Проведение сравнительного анализа цен и результатов опроса респондентов текущего 2021 г. с идентичными данными, полученными нами в рамках работы за прошедший 2020 г. с целью выявления изменения цен и ассортимента продукции. На основании новых данных, с учётом изученной научно-технической литературой прошлого и нынешнего годов, предложить рецептуры мармелада и пастилы из натурального растительного сырья повышенной биологической ценности, обосновав при этом выбор используемых рецептурных компонентов.

\section{РЕЗУЛЬТАТЫ ИССЛЕДОВАНИЯ}

Анализ научно-технической литературы в области совершенствования рецептур классической пастилы позволил сделать вывод о том, что исследования учёных направлены на повышение биологической ценности данного МПИ.

Например, А. В. Альпертом была предложена рецептура пастилы, с помощью которой продукт будет являться полезным и функциональным. Способ изготовления данного вида кондитерского изделия с полезными свойствами включает в себя соединение основного сырья с растительным ингредиентом в виде яблочного пектина, а также предусматривает структурообразование пастильной массы. При этом производят подготовку пектино-сахаро-паточного сиропа, а также пастильной массы, состоящей из яблочного пюре, пектино-сахаро-паточного сиропа и сухого яичного белка, разливку пастильной массы, её структурообразование при температуре $9 \pm 1{ }^{\circ} \mathrm{C}$ около 15 мин, подсушку пастильного пласта при температуре $39 \pm 1{ }^{\circ} \mathrm{C}$, его нарезку на отдельные изделия, сушку пастилы при температуре $47,5 \pm 7,5{ }^{\circ} \mathrm{C}$ в течение 4,5 ч, охлаждение при комнатной температуре примерно 1-1,5 ч, обсыпку пастилы сахарной пудрой при следующем соотношении компонентов (мас.\%): сахар-песок - 8,0-9,0; яблочное пюре 88,5-89,0; яблочный пектин - 1,5-2,0; сухой яичный белок - 1,0 [5].

В пастильной массе по классической рецептуре концентрация сахара составляет около 24 \%. После сушки этот показатель увеличивается почти в 1,5-2 раза в зависимости от конечного содержания влаги в продукте. Высокое содержание сахара в десерте может стать причиной отказа широкого круга потребителей от приобретения данного продукта. Именно поэтому возникает необходимость понижения количества сахара в рецептуре 
классической пастилы. Исследование М. Н. Альшевской с целью научного обоснования технологического процесса и рецептуры бесклеевой пастилы проводили на кафедре технологии продуктов питания ФГБОУ ВО «КГТУ». Объектом данной работы являлись сухой яичный белок и яблоки «Ренет», выращиваемые в Калининградской области. Из плодов изготовили пюре по следующей технологии: запекали при температуре $180-200{ }^{\circ} \mathrm{C}$ в течение 15 мин, после охлаждения массы протирали через сито, получая пюре. Показана возможность производства бесклеевой пастилы на основе сырья, выращиваемого на территории Калининградской области, обоснована целесообразность использования в технологии ее производства сухого яичного белка. Экспериментально были установлены сроки годности готового продукта, также были исследованы его органолептические показатели [1].

В настоящее время рост хронических заболеваний взрослого населения по таким группам, как сердечно-сосудистые и онкологические заболевания, болезни желудочнокишечного тракта и обмена веществ требует расширения ассортимента изделий профилактического направления с включением в них физиологически функциональных пищевых ингредиентов. В связи с этим, А. М. Чистяков из КемТИПП разработал следующую рецептуру для изготовления пастилы. Изобретение относится к производству продукта специализированного назначения. Предложен способ производства пастилы с использованием сахарозаменителей, который включает в себя подготовку сырья и добавок, приготовление агарового сиропа и обогащенной пастильной массы, разливку пастильной массы, структурообразование и подсушку пласта и доведения до надлежащего для употребления потребителем вида (т. е. нарезку изделия, обсыпку какао-порошком, упаковку, маркировку). В качестве сахарозаменителей используют сорбит в сочетании с гликозил стевиозидом «Кристалл», а добавка представляет собой органическую йодсодержащую добавку «Йодказеин». Изобретение позволяет получить пастилу на сорбите и стевиозиде с использованием биологической активной добавки «Йодказеин» и служит функциональным продуктом в комплексной диетотерапии людей, страдающих сахарным диабетом, а также в комплексной диетотерапии как дополнительный источник йода [8].

На сегодняшний день процент авитаминоза у населения страны и в мире в целом достаточно большой, поэтому так важно производить продукты питания, которые будут иметь не только приятный вкус, цвет и форму, но и нести пользу для окружающей среды и здоровья человека. Т. Н. Иванова и соавторы, как и многие заинтересованные, обращаются к этой проблеме. Они запатентовали свой вариант решения данной задачи пастила с овощными добавками. Для изготовления данного продукта яблочное и овощное пюре готовят следующим образом: яблоки, свеклу или морковь промывают, очищают от примесей, семечек и плодоножек, запекают на противнях при температуре $120{ }^{\circ} \mathrm{C}$, яблоки - в течение 40 мин, свеклу - в течение 2 ч, морковь - в течение 1 ч. Затем протирают печеные плоды и овощи для приготовления пюре, сбивают в течение 30 мин. В нужной пропорции смешивают пюре из яблок и моркови, а во втором случае - из яблок и свеклы и сбивают с сахаром. Пропорции следующие: яблочное пюре - $90 \%$, морковное или свекольное пюре - 10 \%. Пропорции сахара и пюре $1: 1$. Агар смешивается с водой и сахаром (получается патока, в данном случае на 250 г пюре берется 5 г агара, 160 г сахара и 60 г воды), подогревается до растворения. Пока сироп остывает, в пюре добавляют белок (на 250 г пюре - 10 г белка) и сбивают. После этого вносятся ванилин и лимонная кислота, затем вливается сироп тонкой струей и сбивается на низкой скорости. Полученная смесь выливается в форму, застеленную бумагой для выпечки. Оптимальная толщина смеси - 20 мм. Застывание происходит при температуре $23-25{ }^{\circ} \mathrm{C}$ в течение 5-6 ч. Поверхность пастилы посыпается сахарной пудрой. В данной необычной рецептуре уровень витаминов намного выше, чем во фруктовой пастиле [4]. 
Нередко в рецептуру пастилы добавляют бурые водоросли. Ламинария относится к функциональному питанию, при его приеме повышается физическая работоспособность. Экспериментальные исследования показали, что прием ламинарии увеличивает физическую выносливость и предупреждает развитие оксидативного напряжения в крови. От него практически невозможно поправиться, поэтому данный эксперимент является, несомненно, значимым. Энергетическая ценность для 100 г продукта - 350 ккал, белков содержится 12, углеводов - 70 и жиров - 0,5 г [3].

Совершенствование рецептуры кондитерского изделия пастилы происходит не только за счет выявление нового подходящего сырья, но и за счет сравнительного анализа, уже используемого в производстве. Для исследования было выбрано два вида сырья слива сорта «Габровская» и облепиха сорта «Сибирская», которые выращены и предоставлены Институтом горного животноводства и земледелия «Троян» для разработки инновационного продукта. Установлено, что в соответствии с изученными параметрами, слива сорта «Габровская» имеет высокие уровни содержания сухих веществ, активной кислотности и антиоксидантной активности. По цвету и содержанию общих полифенолов в результатах лидировало сырье облепиха сорта «Сибирская». Сравнительный анализ разработанного ассортимента пастил показал, что инновационный продукт «Пастила из чернослива и облепихи» показал более высокие значения антиоксидантной активности и общего содержания полифенолов. Этот продукт отличается лучшими качественными и количественными цветовыми характеристиками, и получил более высокий балл общей сенсорной оценки по сравнению с одноплодным продуктом - пастила из чернослива [2].

Таким образом, анализ современных научных исследований в области производства пастилы показал целесообразность и перспективность усовершенствования рецептуры, обогащение пастилы полезными веществами в сторону поддержания и улучшения здоровья людей.

Мармелад представляет из себя МПИ, получаемое за счёт уваривания сахара и патоки с рядом других компонентов - раствора студнеобразователя, а также ягодных или фруктовых соков или пюре на их основе. В отличие от пастилы, мармелад не является новым объектом исследования в рамках нашей работы - актуальность совершенствования его рецептур, а также основные тенденции при его производстве были рассмотрены в работе прошлого года и за прошедшее время изменениям не подверглись [6].

Основываясь на данных прошлых исследований и новый обзор научно-технической литературы, можно заключить, что пастила имеет схожие с мармеладом тенденции в производстве. Они заключаются в частичной или полной замены сахара в рецептурах обоих этих изделий, а также в обогащении их рецептур полезными для человека веществами. В производстве пастилы также наблюдается тенденция использования в качестве пенообразователя сухого яичного белка с целью его более безопасного использования в термически необработанном виде, а также простом и долгом сроке хранения и для повышения сроков хранения пастилы.

Для оценки рынка МПИ на 2021 г. был изучен ассортимент магазинов г. Калининград. По результатам маркетинговых исследований сделан вывод о том, что по сравнению с предыдущим годом цены остались неизменными, однако вырос ассортимент продаваемой продукции (преимущественно российского производства), что, в свою очередь, говорит о том, что мармелад по прежнему является актуальным для рынка кондитерским изделием, пользующийся спросом среди населения города.

В крупных торговых сетях Калининграда «Spar», «Виктория» и «Пятёрочка» на прилавках преобладает клеевая пастила. В среднем данная продукция за 100 г имеет стоимость 50,66 руб. Однако в ее составе преобладает высокое содержание сахара, пищевые ароматизаторы и красители. Пастила типа Белевской в среднем за 150 г имеет стоимость 146,66 руб. и представлена в небольшом количестве одного производителя, что 
дает почву для расширения ассортимента и снижения себестоимости за счет использования регионального сырья.

Согласно исследованиям по составу мармеладной массы, желирующим агентом в составе рассматриваемой продукции в основном выступает пектин. В составе всех видов мармелада имеется патока и сахар, что говорит о том, что его витаминно-минеральный состав очень беден.

В среднем мармеладная продукция за 100 г имеет стоимость равную 21-33 руб. Мармеладная масса дорожает в зависимости от содержания в ней натуральных ингредиентов. Модифицированный крахмал в составе мармелада зарубежных производителей увеличивает цену на исследуемый продукт (дополнительно накрутку цены осуществляет факт зарубежного происхождения продукта). Также на стоимость продукции влияет сам магазин. Например, мармеладная продукция в сети «Bon Ville» гораздо дороже, чем тот же вид мармелада в тех же более распространенных магазинах «Виктория».

По результатам исследований сделан вывод о том, что наиболее дешевым мармеладом является продукция производителя ООО «Славконд» (14-21 руб. за 100 г), самым же дорогим - продукция производителя Sunkist (331,6 руб. за 100 г).

Выявление спроса как на мармелад, так и на пастилу проводилось путём интернетопроса потребителей сладостей в виде анкетирования. Число респондентов составило 60 чел. Их число невелико, однако этого оказалось достаточным для понимания ситуации спроса на исследуемые продукты.

На рис. 1 приведена диаграмма, которая показывает, что по состоянию на 2021 г., конфеты и карамель являются самыми популярными сахаристыми изделиями, однако группа МПИ также занимает лидирующее положение среди всех представленных групп сахаристых изделий. Согласно исследованиям, мармелад пользуется большой популярностью среди людей в возрасте до 20 лет.

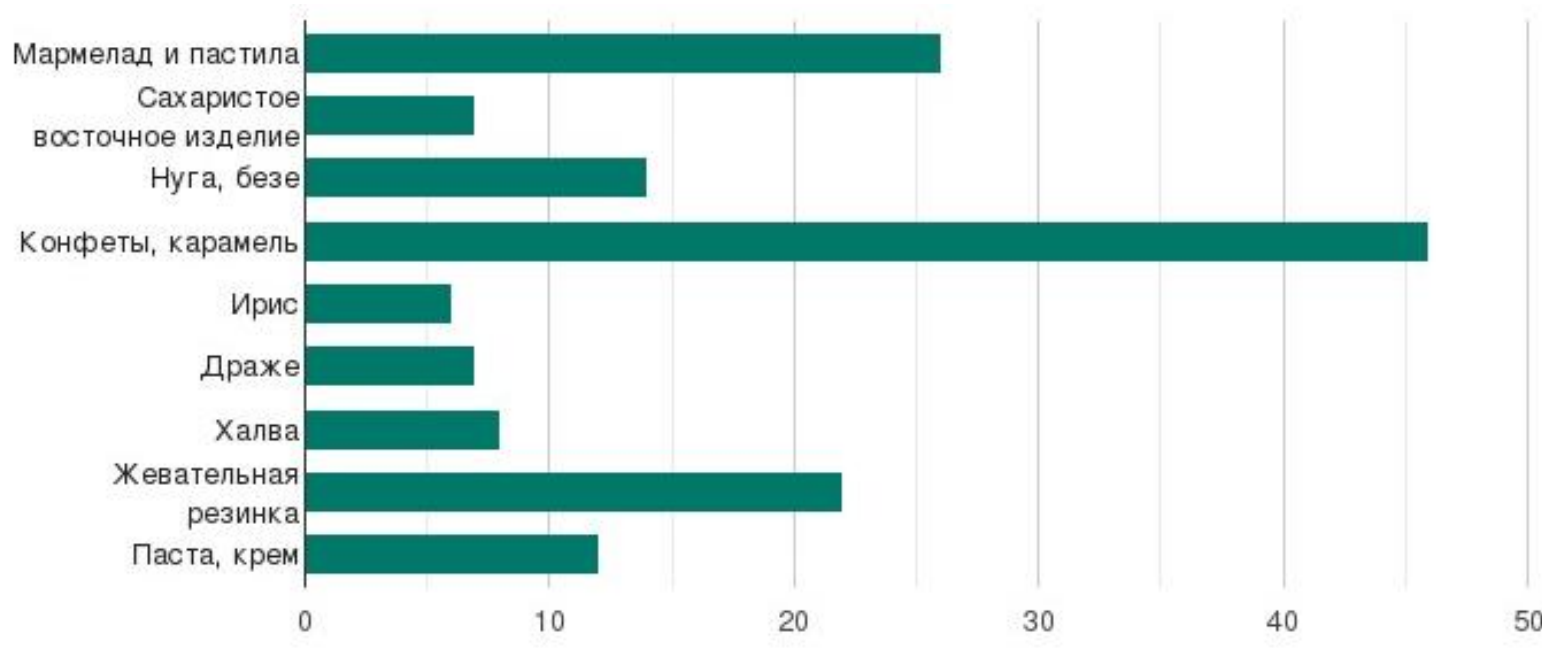

Рисунок 1 - Распределение респондентов по предпочтениям в выборе кондитерских изделий

Диаграмма А на рис. 2 демонстрирует заинтересованность потребителя именно в жевательном мармеладе. Большинство респондентов предпочло мармелад именно этой консистенции. Процесс жевания может играть роль антидепрессанта, что предположительно является объяснением к выбору жевательного мармелада.

Диаграмма Б на том же рисунке показывает, что население г. Калининграда приветствует обогащение мармелада и пастилы различным природным сырьем, 
повышающим биологическую ценность продукта. Большинство опрашиваемых предпочли обогащение сырьем в виде ягод, выращиваемых на территории Калининградской области.
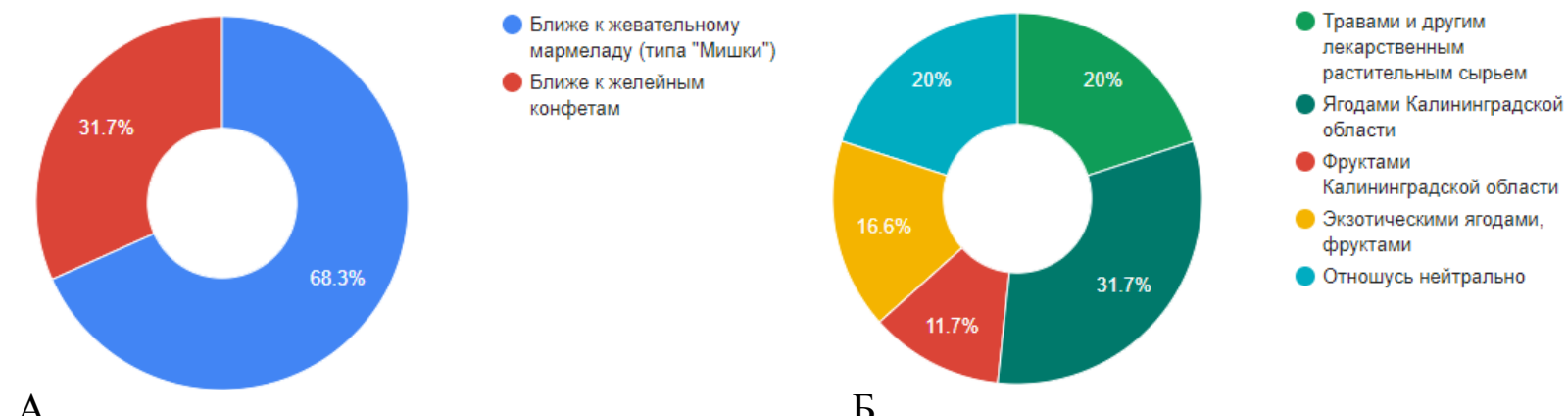

Б

Рисунок 2 - Распределение респондентов по результатам ответа на вопрос «Какую консистенцию мармелада Вы предпочитаете для употребления в пищу?» (А); распределение респондентов по результатам ответа на вопрос «Хотели бы Вы попробовать мармеладно-пастильные изделия повышенной биологической ценности, обогащенные?»

\section{ОБОСНОВАНИЕ ВЫБОРА СЫРЬЯ И ТЕХНОЛОГИЯ ПРИГОТОВЛЕНИЯ МАРМЕЛАДА И ПАСТИЛЫ}

Яблоко - основной ингредиент пастилы, содержит большое количество пектиновых веществ, $\mathrm{Fe}, \mathrm{K}, \mathrm{Cu}$ и витамина С. Однако известно, что для их полноценного усвоения необходимы $\mathrm{Mn}, \mathrm{Si}$ и пищевые волокна. Данные вещества можно восполнить путем введения в состав черники обыкновенной (Vaccínium myrtíllus).

Предложены две рецептуры приготовления бесклеевой пастилы. Сущность технологии приготовления первой рецептуры (пастила «Яблочная») заключается в подготовке яблок, которая включает в себя мойку сырья, высушивание, запекание при 180-200 ${ }^{\circ} \mathrm{C}$ до мягкости в течение 20-30 мин, удаление косточек и кожуры, перетирание в пюре и сбивания в течение 5 мин до воздушного состояния. Далее следует подготовка белково-сахарной массы, включающая сбивание в стойкую пену. Затем перемешивают массы, разливают на противни толщиной 1-1,5 cм, сушат при $80{ }^{\circ} \mathrm{C}$ около 8 ч, прослаивают белково-сахарной массой, досушивают при той же температуре в течение 2 ч, охлаждают и опудривают готовое кондитерское изделие.

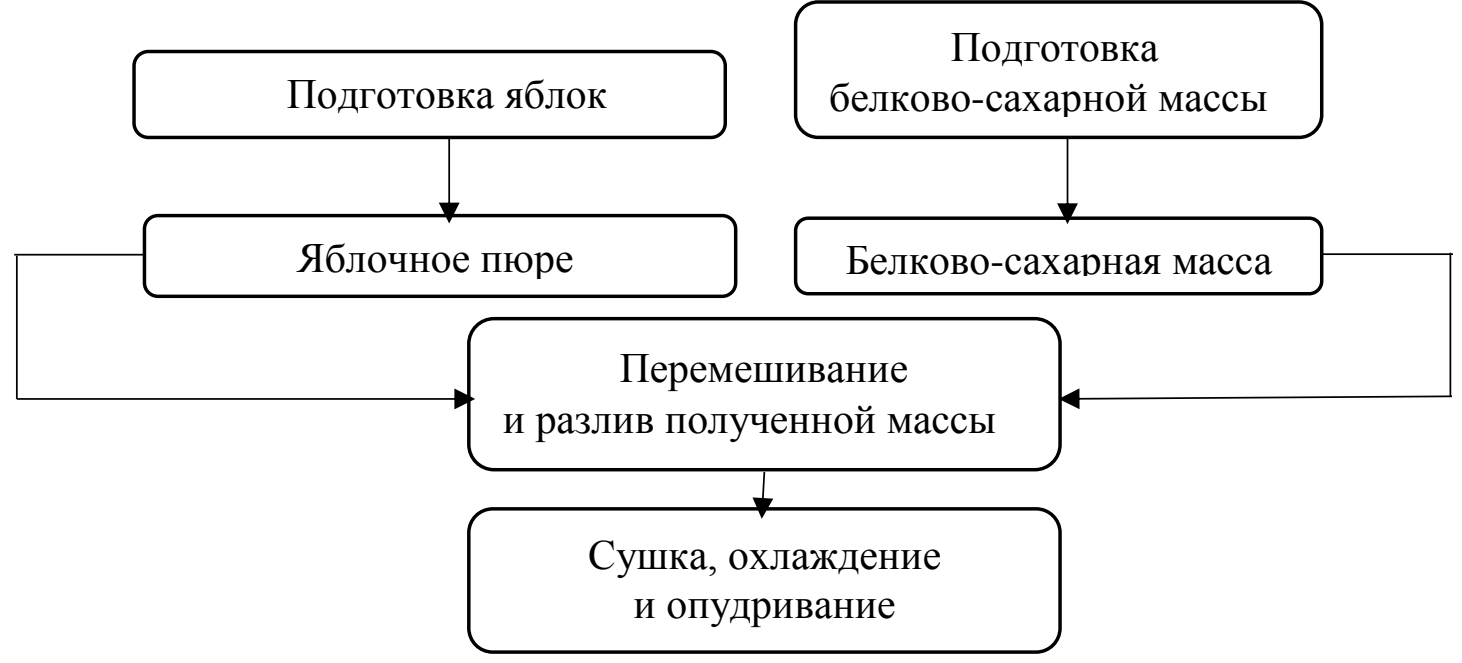

Рисунок 3 - Технологическая схема приготовления рецептуры пастилы «Яблочная» 
Технология производства второй рецептуры (пастила «Яблочная с черникой») включает те же действия, что и в первой рецептуре до момента соединения белковой массы с яблочным пюре. В данном случае часть белковой массы смешивается с черникой (в виде пюре), в которую заранее добавляется пектин, смешанный с сахаром в заданном соотношении (чтобы частички пектина не разбухли в жидком черничном пюре и не получился слипнувшийся комок). Далее все процессы производства аналогичны первой рецептуре.

Оба готовых продукта обладают такими органолептическими характеристиками как: целостный внешний вид, коричневый цвет и блеск на поверхности, равномерная структура, вкус в меру сладкий с небольшой кислинкой, запах, свойственный данному продукту, по консистенции пастила целостная, слегка затяжистая.

Натуральным растительным сырьём при производстве мармелада предлагаемой рецептуры выступают плоды и листья шиповника, ягоды голубики, а также сушеные ягоды винограда Кишмиш. Данные по составу используемого сырья представлены в таблице [7].

Таблица - Состав растительного сырья, используемого в рецептуре при приготовлении мармелада

\begin{tabular}{|l|c|c|c|c|c|c|c|c|c|}
\hline \multicolumn{1}{|c|}{ Ягода } & $\mathrm{Na}$ & $\mathrm{K}$ & $\mathrm{Ca}$ & $\mathrm{Mg}$ & $\mathrm{P}$ & $\mathrm{Fe}$ & $\mathrm{B} 1$ & $\mathrm{~B} 2$ & $\mathrm{C}$ \\
\hline Виноград & 26 & 255 & 30 & 17 & 22 & 0,6 & 0,05 & 0,02 & 6 \\
\hline Кишмиш & 117 & 830 & 80 & 42 & 129 & 3 & 0,15 & 0,08 & 0 \\
\hline $\begin{array}{l}\text { Смородина } \\
\text { белая }\end{array}$ & 2 & 270 & 36 & 9 & 23 & 0,5 & 0,01 & 0,02 & 40 \\
\hline $\begin{array}{l}\text { Смородина } \\
\text { красная }\end{array}$ & 21 & 275 & 36 & 17 & 33 & 0,9 & 0,01 & 0,03 & 25 \\
\hline $\begin{array}{l}\text { Смородина } \\
\text { черная }\end{array}$ & 32 & 350 & 36 & 31 & 33 & 1,3 & 0,03 & 0,04 & 200 \\
\hline $\begin{array}{l}\text { Шиповник } \\
\text { сушеный }\end{array}$ & 11 & 50 & 60 & 17 & 17 & 3 & 0,07 & 0,3 & 1000 \\
\hline
\end{tabular}

По данным таблицы видно, что кишмиш превосходит остальные ягоды по количественному содержанию натрия, калия, кальция, витамина Р, железа. В качестве «агента», дающего мармеладу его окраску, а также более сладкий вкус, выступает голубика. Ягоды голубики укрепляют стенки кровеносных сосудов, нормализуют работу органов пищеварения и сердца, усиливают обмен веществ и действие сахаропонижающих препаратов. Загустителем выступает желатин.

Шиповник выступает как основной источник витамина С. Листья шиповника богаты фенолкарбоновыми кислотами и их производными, выступающими в качестве антиоксидантов. Разрабатываемая рецептура мармелада может быть направлена на профилактику минеральной недостаточности организма человека.

Сущность предложенного технологического решения заключается в следующем. Осуществлялось параллельное приготовление двух отваров: из листьев и из плодов шиповника, которые были погружены в горячую воду, после чего подверглись 30минутному томлению на плите с дальнейшим часовым отстаиванием. Важным моментом является сохранение витамина $\mathrm{C}$ в составе мармеладной массы. Рецептура готовится без доступа света и кислорода воздуха, без доведения воды до кипения.

Параллельно идет подготовка ягодного сырья - ягод голубики и кишмиша путем измельчения в блендере с добавлением сахара. Размешивая компоненты до однородной массы, получают конечный раствор, который переливается в емкости. 
Мармеладная масса второй рецептуры готовится по такой же технологии, однако включает в себя лишь компоненты шиповника - отвары его листьев и плодов. В целом дегустаторы высоко оценили органолептические показатели готовых изделий профильным методом. Мармелад, приготавливаемый по предложенным рецептурам, имеет следующие органолептические показатели: правильная форма с четким контуром, поверхность глянцевая, без обсыпки. Без посторонних привкусов и запахов. Вкус соответствует заявленным компонентам рецептур.

\section{ЗАКЛЮЧЕНИЕ}

Пастила и мармелад, являясь МПИ, имеют схожесть в тенденциях их производства. По результатам маркетинговых исследований сделан вывод о том, что ассортимент продаваемых в магазинах г. Калининграда МПИ довольно широк. Стоимость МПИ в сильно варьируется, в среднем составляя 21-33 руб. за 100 г для мармелада и 50,66 руб. для пастилы. Обогащенные МПИ, по результатам интернет-опроса, приветствуются и потенциально будут иметь спрос у населения. По сравнению с 2020 г. цены на исследуемые продукты остались неизменными, а ассортимент - более расширенным. Были предложены технологические схемы производства мармелада и пастилы повышенной биологической ценности. Готовая продукция может быть направлена на восполнение витаминно-минеральной недостаточности в организме человека.

\section{СПИСОК ЛИТЕРАТУРЫ}

1. Альшевская, М. Н. Научное обоснование совершенствования технологических параметров бесклеевой пастилы / М. Н Альшевская, В. Ю. Трофимова // Вестник КамчатГТУ - 2018. - № 46. - С. 15-22.

2. Иванова, П. Х. Разработка инновационного высококонцентрированного продукта «Пастила из синих сортов сливы домашней и облепихи» / П. Х. Иванова, Т. М. Михова // Медико-биологические проблемы здоровья человека - 2019. - № 14. - С. 204-211.

3. Норадько, О. И. Разработка технологии кондитерских изделий (пастилы) на основе тыквы с добавлением ламинарии: маг. дис. 19.04.05 / Норадько Олеся Игоревна; ДВФУ. - Владивосток, 2018.

4. Пат. 2579484 Российская Федерация МПК A23G 3/48, A23G 3/52 Пастила с овощными добавками [Текст] / Т. Н. Иванова, О. В. Евдокимова, Э. А. Пьяникова, Е. В. Неликаева, заявитель и патентообладатель: Федеральное государственное бюджетное образовательное учреждение высшего образования «Юго-Западный государственный университет». - № 2014135589; заявл.: 02.09.2014; 10.04.2016. Бюл. № 10 .

5. Пат. 2637219 Российская Федерация МПК A23G 3/36, A23G 3/50. Способ приготовления пастилы с функциональными свойствами [Текст] / А. В. Альпет, Н. В. Карабаева, Е. В. Каширских, О. Ю. Рубанникова, А. В. Изгарышев, заявитель и патентообладатель Общество с ограниченной ответственностью «Научнопроизводственная Сибирская ореховая компания». - № 2016144234; заявл. 10.11.2016; 01.12.2017. Бюл. № 34.

6. Петрухин, Д. А. Современные тенденции в производстве мармеладо-пастильных изделий / Д. А. Петрухин, Е. Д. Ковалева, Н. Ю. Ключко // Вестник молодежной науки. 2020. - № 3 (25). - С. 1-8.

7. Химический состав российских пищевых продуктов: справочник / под ред. членкорр. МАИ, проф. И. М. Скурихина и акад. РАМН, проф. В. А. Тутельяна. - Москва: ДеЛи принт, 2002. -236 с. 
8. Чистяков, А. М. Способ производства пастилы специализированного назначения на сорбите и стевиозиде, обогащенной добавкой йодказеин: автореф. дис. ... канд. техн. наук / Чистяков Андрей Михайлович; Кемеровский технологический институт пищевой промышленности. - Кемерово, 2018.

\title{
PASTILLES AND MARMALADE TECHNOLOGY WITH INCREASED BIOLOGICAL VALUE
}

\author{
D. A. Petrukhin, student, \\ e-mail: denisrussia2000@gmail.com \\ Kaliningrad State Technical University \\ E. D. Kovaleva, student, \\ e-mail: kovaleva_k_30@mail.ru \\ Kaliningrad State Technical University \\ N. Yu. Kliuchko, PhD, Associate Professor, \\ e-mail: natalya.kluchko@klgtu.ru, \\ Kaliningrad State Technical University
}

All over the world, confectionery products are widespread, among which the so-called marshmallow products occupy a special place. In our country this group is present in a rather wide range and is in great demand among the population, especially among the young. These facts give reason to develop or improve methods to reduce the caloric content of these products, as well as to increase their energy and nutritional value. The patented methods of enriching marshmallow with components beneficial to the human body and the prospects for introducing biologically valuable substances into the recipes of this confectionery product are considered in this article. Several recipes for marmalade and marshmallow, which can be used as a technological basis, considering current trends in the production of marshmallow is proposed.

Keywords: marmalade, marshmallow, enriched product, marmalade and marshmallow products, cooking technology, market research, market analysis 